\title{
Sex pheromone and period gene characterization of Lutzomyia longipalpis sensu lato (Lutz \& Neiva) (Diptera: Psychodidae) from Posadas, Argentina
}

\author{
Oscar D Salomón ${ }^{1 /}$, Alejandra S Araki², James GC Hamilton ${ }^{3}$, \\ Soraya A Acardi ${ }^{4}$, Alexandre A Peixoto ${ }^{2}$ \\ ${ }^{1}$ Centro Nacional de Diagnóstico e Investigación en Endemo-epidemias, Av. Paseo Colon 568, 1063 CA Buenos Aires, Argentina \\ ${ }^{2}$ Laboratório de Biologia Molecular de Insetos, Instituto Oswaldo Cruz-Fiocruz, Rio de Janeiro, RJ, Brasil \\ ${ }^{3}$ Centre for Applied Entomology and Parasitology, Keele University, Staffordshire, United Kingdom \\ ${ }^{4}$ Laboratorio de Biologia Molecular Aplicada, Universidad Nacional de Misiones, Posadas, Argentina
}

Lutzomyia longipalpis s.l. is the primary vector of Leishmania (L.) infantum in the New World. In this study, male Lutzomyia longipalpis specimens from Posadas, Argentina were characterized for two polymorphic markers: the male sex pheromone and the period (per) gene. The male sex pheromone was identified as (S)-9-methylgermacrene- $B$, the same compound produced by Lu. longipalpis from Paraguay and many populations from Brazil. The analysis of per gene sequences revealed that the population from Argentina is significantly differentiated from previously studied Brazilian populations. Marker studies could contribute to the understanding of the distribution and spread of urban American visceral leishmaniasis, thus aiding in the design of regional surveillance and control strategies.

Key words: Lutzomyia longipalpis - sex pheromone - period gene

Fourteen autochthonous human cases of leishmaniasis with visceral involvement were reported at various times and locations in Argentina from 1925-1989. The primary vector of this disease, Lutzomyia longipalpis, was captured only twice in Argentina during this time period; in both cases, the vectors were captured in localities near the city of Posadas, province of Misiones, where there had been no previous reports of visceral leishmaniasis cases (Salomón et al. 2001).

This sparse transmission scenario changed after the southern spread of urban American visceral leishmaniasis (AVL) in Brazil during the last decades of the previous century (Gontijo \& Melo 2004, Lainson \& Rangel 2005). The incidence of AVL changed from sporadic cases to clustered cases in regions such as the state of Mato Grosso do Sul (MS), Brazil (Oliveira et al. 2006, Botelho \& Natal 2009) and, subsequently, Asunción, Paraguay (Canese 2000, Cousiño 2006). In 2004, Lu. longipalpis was captured in the city of Clorinda, Argentina, on the border with Paraguay (Salomón \& Orellano 2005). In 2006, the first human case of AVL associated with Leishmania infantum infected dogs and Lu. longipalpis was reported in the city of Posadas, Argentina (Salomón et al. 2008). Furthermore, from May 2006-November 2009, 39 clustered cases of human AVL, five of them fatal, were reported in

Financial support: HHMI, FIOCRUZ, FAPERJ, CNPq (to AAP) ODS and SAA are a researcher and a fellow, respectively, of the CONICET, Argentina.

+ Corresponding author: odanielsalomon@gmail.com

Received 14 April 2010

Accepted 26 July 2010
Posadas, where thousands of dogs were found to be infected (Fernández et al. 2010). Lu. longipalpis and canine AVL were also identified $350 \mathrm{~km}$ south of Posadas, in Corrientes, Argentina (Salomón et al. 2009b) and in the state of Rio Grande do Sul, Brazil (Souza et al. 2009).

If these southern outbreaks are thought of as a unique emergent urban pattern, then epidemiological studies can be extrapolated among foci (Correa Antonialli et al. 2007, Oliveira et al. 2008, Pangrazio et al. 2009, Salomón et al. 2009a, Fernández et al. 2010) and a common regional control strategy can be proposed. Lu. longipalpis is a species complex with polymorphic markers that show both a heterogeneous geographic distribution and divergent trends; in addition, there are putative differences in vectorial competence among populations (Lainson \& Rangel 2005, Bauzer et al. 2007, Maignon et al. 2008). Therefore, to contribute to the characterization of $\mathrm{Lu}$. longipalpis vectors in the southern AVL foci, two polymorphic markers of individuals from Posadas were studied: the male sex pheromone and the period (per) gene. Both markers have been analyzed in a number of Lu. longipalpis populations from Brazil (Hamilton et al. 1999, 2004, 2005, Bauzer et al. 2002a, b, Araki et al. 2009) and from Paraguay (Brazil et al. 2009).

Homosesquiterpene (C16) and diterpene (C20) are sex pheromones released by male Lu. longipalpis prior to and during courtship, with molecular weights of 218 and 272, respectively. At present, four different sex pheromone-producing populations (chemotypes) are recognized (Hamilton et al. 2004). The expression patterns of the per gene, which controls circadian rhythms and affects interpulse interval periodicity of the male courtship songs in Drosophila melanogaster and close relatives, suggest the existence of two main groups of $L u$. longipalpis in Brazil. One group is represented by a 
single species with males producing burst-type copulation songs and cembrene-1 pheromones. The other group is more heterogeneous and probably represents a number of incipient species producing different combinations of pulse-type songs and pheromones (Araki et al. 2009).

$\mathrm{Lu}$. longipalpis were collected overnight in February 2007 using CDC light traps in the backyard of an urban house in the AVL endemic area of Posadas

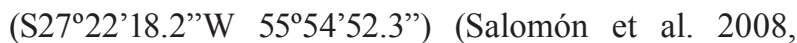
Fernández et al. 2010). One trap was placed in a chicken coop containing 24 chickens and another was placed $25 \mathrm{~m}$ from the chicken coop in a kennel containing two dogs. Taxonomic identifications were made according to the method described by Young and Duncan (1994); Lu. longipalpis was the only species found.

The male specimens used for the pheromone analysis were processed as previously reported for the Paraguayan samples (Brazil et al. 2009). Briefly, 58 males (29 from each site) were placed individually in glass ampoules made from Pasteur pipettes with a small volume of $n$-hexane $(20 \mu \mathrm{L})$ that were then flame sealed. Prior to analysis, extracts were removed from the vials and filtered through glass wool to remove the flies and fly hairs before the volume was reduced to $1 \mu \mathrm{L}$ under $\mathrm{N}_{2}$. Mass spectra and gas chromatography retention times were compared with authentic (S)-9-methylgermacrene-B (Hamilton et al. 1999). Peak enhancement studies were performed by co-injecting extracts of $L u$. longipalpis from Lapinha (Minas Gerais, Brazil) and $\mathrm{Lu}$. longipalpis from Posadas. Gas chromatography coupled mass spectrometry (GC/MS) analysis was carried out on a Hewlett Packard 5890 II GC with a HP-5MS capillary column, $30 \mathrm{~m} \times 0.25 \mathrm{~mm}$ i.d. and $0.25 \mathrm{~mm}$ film thickness that was directly coupled to a Hewlett Packard 5972A bench top MS (EI, 70eV, $\left.165^{\circ} \mathrm{C}\right)$. Samples were introduced via an on-column injector $\left(40^{\circ} \mathrm{C}\right)$. The GC was temperature programmed for an initial 2 min at $40^{\circ} \mathrm{C}$, followed by an increase of $10^{\circ} \mathrm{C} \mathrm{m^{-1 }}$ to a final isothermal period at $250^{\circ} \mathrm{C}(10 \mathrm{~min})$.

The pheromone of the male Lu. longipalpis complex member from Argentina was identified as $(S)$-9-methylgermacrene-B, by comparison of mass spectral [218 $(\mathrm{M}+, 22), 165(49), 135(76), 121(100), 119(40), 107(62)$, 93(71), 91(44), 79(40), 67(78), 41(66)] and retention time data. Peak enhancement studies confirmed that Argentinian Lu. longipalpis males produce the same compound as Lu. longipalpis from Paraguay (Brazil et al. 2009) and Brazil (Hamilton et al. 1999, 2005, Araki et al. 2009).

The per gene sequences were generated as reported previously (Bauzer et al. 2002a, b, Araki et al. 2009). Briefly, sand fly DNA was extracted according to Jowett (1998) and a 266-bp fragment of the Lu. longipalpis per gene was amplified as described in Bauzer et al. (2002b). PCR fragments were purified using a Wizard PCR prep kit (Promega) and cloned using a pMOS Blunt Ended cloning kit (GE Healthcare). Plasmid DNA was prepared using the alkaline lysis method in 96-well micro-plates and was filtered in Multiscreen-filter plates. Sequencing of cloned fragments was performed using an ABI 3730 DNA Analyzer and an ABI Prism Big Dye Terminator Cycle Sequencing Ready Reaction V3.1 kit (Applied
Biosystems). Between five and eight sequences per individual were edited and aligned using BioEdit software version 7.0.9.0 (Hall 1999). Fst analysis was performed using both DnaSP 5.1 and Proseq software (Filatov 2002, Librado \& Rozas 2009).

Sequences were obtained from $29 \mathrm{Lu}$. longipalpis males collected from the two sites in Posadas. There was no evidence of microgeographic differentiation between sites (Fst $=-0.03 ; p>0.05)$; therefore, the two samples were pooled and compared to the previously published sequences of Brazilian populations of $\mathrm{Lu}$. longipalpis (Bauzer et al. 2002a, b, Araki et al. 2009). The results indicated that the population from Argentina is different from previously analyzed Brazilian populations, with significant $(p<0.01)$ Fst values ranging from 0.17-0.43. These values are quite high and suggest that the Posadas population of Lu. longipalpis might be a different sibling species from those found in Northeast and Southeast Brazil (Araki et al. 2009).

These findings illustrate the importance of studies further evaluating the relationship between the $\mathrm{Lu}$. longipalpis populations that are producing the emergent phenomena of urban AVL outbreaks in MS, Paraguay and Argentina over the last decade. These studies, together with research on the ecological and social variables that modulate the outbreaks and dispersion of both the parasites and vectors, could aid in the design of improved regional surveillance and control strategies based on vector behavior and distribution (Salomón et al. 2009a, Bray et al. 2010, Fernández et al. 2010).

\section{REFERENCES}

Araki AS, Vigoder FM, Bauzer LG, Ferreira GE, Souza NA, Araújo IB, Hamilton JG, Brazil RP, Peixoto AA 2009. Molecular and behavioral differentiation among Brazilian populations of Lutzomyia longipalpis (Diptera: Psychodidae: Phlebotominae). PLoS Negl Trop Dis 3: e365.

Bauzer LG, Gesto JS, Souza NA, Ward RD, Hamilton JG, Kyriacou CP, Peixoto AA 2002a. Molecular divergence in the period gene between two putative sympatric species of the Lutzomyia longipalpis complex. Mol Biol Evol 19: 1624-1627.

Bauzer LG, Souza NA, Maingon RD, Peixoto AA 2007. Lutzomyia longipalpis in Brazil: a complex or a single species? A mini-review. Mem Inst Oswaldo Cruz 102: 1-12.

Bauzer LG, Souza NA, Ward RD, Kyriacou CP, Peixoto AA 2002b. The period gene and genetic differentiation between three Brazilian populations of Lutzomyia longipalpis. Insect Mol Biol 11: 315-323.

Botelho AC, Natal D 2009. Primeira descrição epidemiológica da leishmaniose visceral em Campo Grande, estado de Mato Grosso do Sul. Rev Soc Bras Med Trop 42: 503-508.

Bray DP, Alves GB, Dorval ME, Brazil RP, Hamilton JG 2010. Synthetic sex pheromone attracts the leishmaniasis vector Lutzomyia longipalpis to experimental chicken sheds treated with insecticide. Parasit Vectors 3: 16.

Brazil RP, Caballero NN, Hamilton JG 2009. Identification of the sex pheromone of Lutzomyia longipalpis (Lutz \& Neiva, 1912) (Diptera: Psychodidae) from Asunción, Paraguay. Parasit Vectors 2: 51.

Canese A 2000. Leishmaniosis visceral canina en el área metropolitana de la "Gran Asunción", Paraguay. Medicina (Buenos Aires) (Suppl. III) 60: 65. 
Correa Antonialli SA, Torres TG, Paranhos Filho AC, Tolezano JE 2007. Spatial analysis of American visceral leishmaniasis in Mato Grosso do Sul state, central Brazil. J Infect 54: 509-514.

Cousiño B 2006. Vigilancia y control de la leishmaniasis en Paraguay. In Panaftosa, informe final de la Reunión de Expertos OPS/OMS sobre leishmaniasis visceral en las Américas, Panaftosa, Rio de Janeiro, $152 \mathrm{pp}$.

Fernández MS, Salomón OD, Cavia R, Pérez AA, Acardi AS, Guccione JD 2010. Lutzomyia longipalpis spatial distribution and association with environmental variables in an urban focus of visceral leishmaniasis, Misiones, Argentina. Acta Trop 114: 81-87.

Filatov DA 2002. PROSEQ: a software for preparation and evolutionary analysis of DNA sequence data sets. Mol Ecol Notes 2: 621-624.

Gontijo CMF, Melo MN 2004. Leishmaniose visceral no Brasil: quadro atual, desafios e perspectivas. Rev Bras Epidemiol 7: 338-349.

Hall TA 1999. BioEdit: a user-friendly biological sequence alignment editor and analysis program for Windows 95/98/NT. Nucl Acids Symp Ser 41: 95-98.

Hamilton JG, Brazil RP, Maingon R 2004. A fourth chemotype of Lutzomyia longipalpis (Diptera: Psychodidae) from Jaibas, Minas Gerais state, Brazil. J Med Entomol 41: 1021-1026.

Hamilton JG, Ibbotson HC, Hooper AM, Mori K, Pickett JA, Sano S 1999. 9-methylgermacrene-B confirmed by synthesis as the sex pheromone of the sandfly Lutzomyia longipalpis from Lapinha, Brazil, and the absolute stereochemistry defined as 9S. Chem Comm 8: 2335-2336.

Hamilton JG, Maingon RD, Alexander B, Ward RD, Brazil RP 2005. Analysis of the sex pheromone extract of individual male Lutzomyia longipalpis sandflies from six regions in Brazil. Med Vet Entomol 19: 480-488.

Jowett T 1998. Preparation of nucleic acids. In DB Roberts (ed.), Drosophila: a practical approach, IRL Press, Oxford, p. 347-371.

Lainson R, Rangel EF 2005. Lutzomyia longipalpis and the eco-epidemiology of American visceral leishmaniasis, with particular reference to Brazil - A review. Mem Inst Oswaldo Cruz 100: 811-827.

Librado P, Rozas J 2009. DnaSP v5: a software for comprehensive analysis of DNA polymorphism data. Bioinformatics 25: 1451-1452.

Maignon RD, Ward RD, Hamilton JG, Bauzer LG, Peixoto AA 2008. The Lutzomyia longipalpis species complex: does population sub-structure matter to Leishmania transmission? Trends Parasitol 24: 12-17.
Oliveira AG, Galati EA, Fernandes CE, Dorval ME, Brazil RP 2008. Seasonal variation of Lutzomyia longipalpis (Lutz \& Neiva, 1912) (Diptera: Psychodidae: Phlebotominae) in endemic area of visceral leishmaniasis, Campo Grande, state of Mato Grosso do Sul, Brazil. Acta Trop 105: 55-61.

Oliveira AG, Galati EAB, Oliveira O, Oliveira GR, Espindola IAC, Dorval MEC, Brazil RP 2006. Abundance of Lutzomyia longipalpis (Diptera: Psychodidae: Phlebotominae) and urban transmission of visceral leishmaniasis in Campo Grande, state of Mato Grosso do Sul, Brazil. Mem Inst Oswaldo Cruz 101: 869-874.

Pangrazio KK, Costa EA, Amarilla SP, Cino AG, Silva TM, Paixão TA, Costa LF, Dengues EG, Diaz AA, Santos RL 2009. Tissue distribution of Leishmania chagasi and lesions in transplacentally infected fetuses from symptomatic and asymptomatic naturally infected bitches. Vet Parasitol 165: 327-331.

Salomón OD, Orellano PW 2005. Lutzomyia longipalpis in Clorinda, Formosa province, an area of potential visceral leishmaniasis transmission in Argentina. Mem Inst Oswaldo Cruz 100: 475-476.

Salomón OD, Quintana MG, Bruno MR, Quiriconi RV, Cabral V 2009a. Visceral leishmaniasis in border areas: clustered distribution of phlebotomine sand flies in Clorinda, Argentina. Mem Inst Oswaldo Cruz 104: 801-804.

Salomón OD, Ramos LK, Quintana MG, Acardi SA, Santini MS, Schneider A 2009b. Distribución de vectores de leishmaniasis visceral en la provincia de Corrientes, 2008. Medicina (Buenos Aires) 69: 625-630.

Salomón OD, Sinagra A, Nevot MC, Barberian G, Paulin P, Estevez JO, Riarte A, Estevez J 2008. First visceral leishmaniasis focus in Argentina. Mem Inst Oswaldo Cruz 103: 109-111.

Salomón OD, Sosa Estani S, Rossi GC, Spinelli GR 2001. Presencia de Lutzomyia longipalpis y la situación de la leishmaniasis visceral en Argentina. Medicina (Buenos Aires) 61: 174-178.

Souza GD, Santos E, Andrade Filho JD 2009. The first report of the main vector of visceral leishmaniasis in America, Lutzomyia longipalpis (Lutz \& Neiva) (Diptera: Psychodidae: Phlebotominae), in the state of Rio Grande do Sul, Brazil. Mem Inst Oswaldo Cruz 104: 1181-1182.

Young DG, Duncan MA 1994. Guide to the identification and geographic distribution of Lutzomyia sand flies in Mexico, the West Indies, Central and South America (Diptera: Psychodidae). Mem Amer Entomol Inst 54: 1-881. 